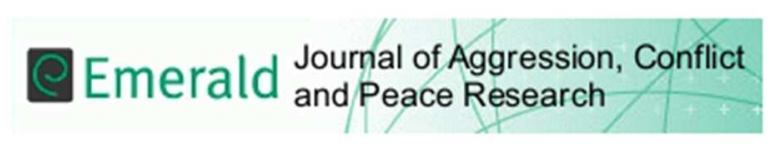

\title{
Personality Dimensions and Attitudes Towards Peace and War
}

\begin{tabular}{|r|l|}
\hline Journal: & Journal of Aggression, Conflict and Peace Research \\
\hline Manuscript ID & JACPR-05-2016-0231.R3 \\
\hline Manuscript Type: & Empirical Paper \\
\hline Keywords: & personality, peace, war, attitudes, authoritarianism, traits \\
\hline \multicolumn{2}{|}{} \\
\hline
\end{tabular}

\section{SCHOLARONE ${ }^{\text {Ix }}$ \\ Manuscripts}


1

2

3

4

5

6

7

8

9

10

11

Personality Dimensions and Attitudes Towards Peace and War - 1

Personality Dimensions and Attitudes Towards Peace and War

\section{ACKNOWLEDGMENTS}

We would like to thank Joanna Britton and Petra Hajdu for helpful comments on an earlier version of this paper. We also thank Ohad Rosen for collecting most of the Israeli data. The present paper is based in part on a paper presented by Blumberg, Zeligman, Appel, \& Tibon-Czopp (2015) prior to collection of the 2015-16 data covered in the present paper. Readers wishing to use the scales measuring attitudes towards peace and war should contract Boris Bizumic: boris.bizumic@anu.edu.au 
Personality Dimensions and Attitudes Towards Peace and War - 2

\begin{abstract}
Purpose. The present study examined the relationship between major personality dimensions and attitudes towards peace and war.

Design. Three samples--two consisting of British psychology students $(\mathrm{N}=64$ and 121) and one of Israeli students $(\mathrm{N}=80)$, responded to measures of some or all of: Five-Factor inventory; SYMLOG trait form; General Survey (GS) including authoritarianism; Attitudes towards Peace and War; specific attitudes towards peace and war policy.
\end{abstract}

Findings. The general attitude measures were associated with the specific attitudes. Both were associated with authoritarianism but not consistently with other personality dimensions.

Limitations: descriptive findings might not generalize..

Research Implications: Authoritarianism should be measured in any studies of attitudes related to peace, war, conflict and structural violence.

Practical Implications: Practitioners of peace education may first need to address high authoritarianism and low integrative complexity. Also, countering structural violence related, for instance, to poverty or prejudice/discrimination may require a comprehensive approach including collaborative work with clinical psychologists applying both implicit and explicit assessment tools.

Originality/value: Documenting links (and lack of them) among personality variables and attitudes towards peace and war has practical and theoretical value - and may contribute to organizational schemes shaped by personality structure and bearing implications for negotiations. In terms of a paradigm by Morton Deutsch, our results show individual differences in, and associations among, variables relating to the remediable likelihood of parties being differentially likely to find themselves (a) in negatively vs. positively interdependent situations and (b) carrying out effective instead of "bungling" actions. 


\section{Introduction}

Substantial research has linked personality variables with attitudes towards issues related to peace and to international aggression including war (see e.g. Blumberg et al., 2006, pp. 11, 21-23, 51, 71-87). The potential association between personality and mainly individual aggression has been even more heavily researched. In February 2016 the PsycINFO database of psychological research held over 850 records that had both personality and aggression as key words. Nevertheless, little contemporary effort has been directed towards estimating the extent and nature of association between (a) personality factors and (b) attitudes towards peace and war and, particularly, degree of support for (e.g.) military action to pre-empt potential threats.

Like various other dimensions such as masculine-feminine, militarism-pacifism was initially thought to represent a single bipolar unitary dimension (Droba, 1931; Page, 1931; Thrall \& Blumberg, 1963). Subsequent research has indicated, however, that positive attitudes towards peace and negative attitudes towards war are in fact largely independent dimensions (Bizumic, et al., 2013).

Personality. Variability in personality functioning has usually been accounted for by using both explicit and implicit measures. These include self-report inventories (e.g., a Big Five inventory) and performance-based measures (e.g., the Rorschach Inkblot Method). Self-report inventories are particularly sensitive to overt mental states of which people are consciously aware, whereas performance-based measures are relatively more sensitive to underlying traits that individuals may not fully recognize in themselves. However, the boundary between the two kinds of measures may well be fuzzier than is commonly appreciated. Self-report test data can speak also to characterological dispositions of the individual, and performance-based test data can tap also mental states and psychological disorders (Tibon-Czopp \& Weiner, 2016). 
Furthermore, self-report inventories may indicate clearly what people know about themselves but be limited by the accuracy of respondents' self-judgments and their reluctance to describe themselves openly and perhaps unfavourably.

Among self-report inventories, the "Big Five" (five factor) measures have provided one of the most frequently used paradigms for personality traits. Dimensions delineated by the Big Fine are Openness to experience, Conscientiousness, Extraversion, Agreeableness and Neuroticism. The paradigm has been extensively examined (e.g., Costa \& McCrae, 1985; Fiske, 1949; Peabody \& Goldberg, 1989; and, with just ten items, Gosling et al., 2003).

The SYstem for the Multiple Level Observation of Groups (SYMLOG) (Bales \& Cohen, 1979) also provides a useful self-report inventory for assessing personality dimensions. SYMLOG delineates three personality dimensions--Positive-Negative, Dominant-Submissive, and Task-Social. These may represent, at least in part, higher-order dimensions of the Big Five (Blumberg, 2001). Unlike the Big Five paradigm, which has largely lexical origins--based, for example, on extant adjectives in the English language-SYMLOG's origins are in Bales's studies of the dimensions manifest in social interaction.

A further self-report inventory, the General Survey (GS) (Kritzer et al., 1974), delineates four personality dimensions: Authoritarian Conformity, Aggressive Mistrust, Anxiety, and Extraversion. These are assessed with sentences to which participants respond on a Likert-type scale.

Present study. The present study is focused on self-report measures. Broadly similar albeit requiring intensive work to administer and analyse, performance-based measures such as the Rorschach might nevertheless constitute a worthwhile future complement to the present work (see e.g. Tibon, 1998). Accordingly, we have administered the Rorschach to a sub-sample of 21 participants, the data of which we plan to analyse in a future paper.

The current study explores possible associations whereby peace/war attitudes might map onto major 
personality dimensions in the three aforementioned self-report inventories-Big Five, SYMLOG and GS. In one of the few studies explicitly measuring both peace/war attitudes and personality variables, but pre-dating use of contemporary Five Factor measures, Eckhardt and Alcock (1970) found that "ideological factors" were relatively free of significant correlation with personality traits. Previous studies have, however, found that authoritarianism, which is measured by the GS, accounts for variance in attitudes towards peace/war-variance not shared with Big Five nor SYMLOG (see e.g. Thrall \& Blumberg, 1963; Tibon, 1998; Tibon \& Blumberg, 1999). We hypothesize, therefore, associations among authoritarianism, positive attitudes towards war, negative attitudes towards peace, and political conservatism. No prior hypotheses are being put for the Big Five nor SYMLOG.

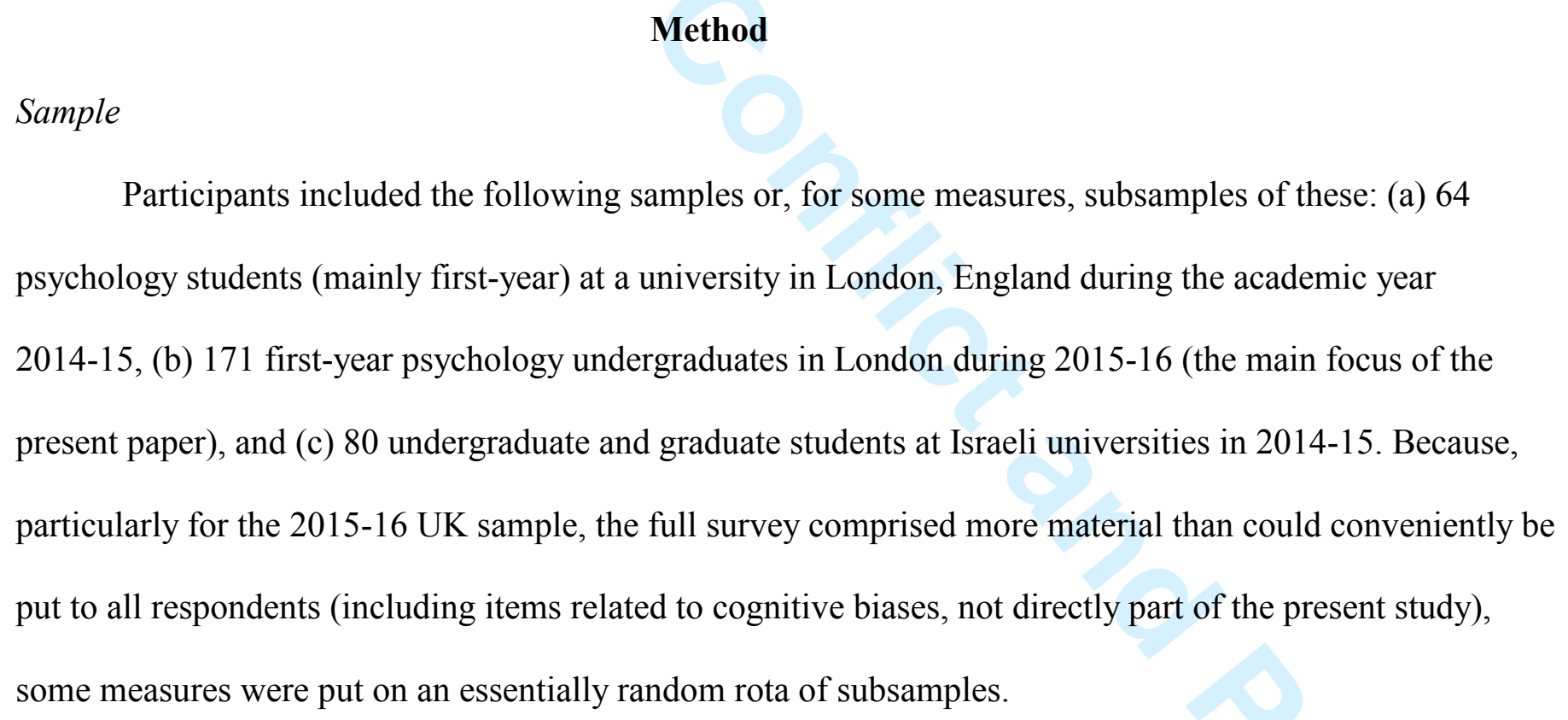

Participants included the following samples or, for some measures, subsamples of these: (a) 64 psychology students (mainly first-year) at a university in London, England during the academic year 2014-15, (b) 171 first-year psychology undergraduates in London during 2015-16 (the main focus of the present paper), and (c) 80 undergraduate and graduate students at Israeli universities in 2014-15. Because, particularly for the 2015-16 UK sample, the full survey comprised more material than could conveniently be put to all respondents (including items related to cognitive biases, not directly part of the present study), some measures were put on an essentially random rota of subsamples.

Our presumption in using these samples is that means and variance of overall scale scores would be of only moderate interest but that correlations and factor structures would be more robust and general, with degrees of congruence across the samples also being useful to learn. Use of two very similar samples plus one from a quite different country, where the difference moreover relates to geographical proximity to major conflicts, facilitates interpreting generality of findings. 
Personality Dimensions and Attitudes Towards Peace and War - 6

\section{Measures}

As a particularly suitable option when time is at a premium, Big Five dimensions can be measured with reasonable reliability and validity by the Ten-Item Personality Inventory (TIPI) (Gosling et al., 2003). Participants rate on a seven-point scale how strongly they agree that they see themselves as, for example, each of the following: dependable, open to new experiences, extraverted, sympathetic, calm. Test-retest reliability of TIPI's five dimensions ranges from .62 to .77; indeed TIPI's validity as an alternative to the standard Big-Five Inventory (BFI) is reflected in correlations ranging similarly from .65 to .87 (Gosling et al., 2003).

The TIPI was translated into Hebrew, using the technique of translation and back translation. However, given the high level of English required in the Israeli universities, participants were provided with both the English and the Hebrew versions and they could choose to which they responded. All of them used the Hebrew version, but they could have used the original English one for comparison.

The three SYMLOG dimensions--Positive-Negative, Up(dominant/assertive)-Down(submissive), and Forward(task-oriented/conforming/predictable)-Backward--can be measured succinctly with a short trait rating form (Blumberg, 2006). This asks one to think of how others in their group would rate them on each of 14 traits, among them warm, dominant, and task-oriented. The translation and administration of the SYMLOG measure to the Israeli sample followed the same procedures as for the TIPI.

Reliability of the present brief scales has been found to be moderate but acceptable; Cronbach's alpha $=.54$ for Up/Down (dominance), .63 for Positive/Negative, and .58 for Forward/Backward (task conforming) (Blumberg, 2006). The correlations between corresponding dimensions on the two forms, the present brief scales and the original trait measures were very high: .88 for Up, .87 for Positive, and .89 for Forward. Although these results capitalize on chance--because many of the same items, including their error, 
are counted on both versions of a scale--it is clear that corresponding dimensions on the two forms are very highly associated. That is, the short form captures over three quarters of the variance of the standard form on a given occasion.

Finally, an eight-item measure of classical authoritarianism is included in the General Survey (GS) (Kritzer et al., 1974). Items are rated on a seven-point scale ranging from strongly disagree to strongly agree. A typical item: "Obedience and respect for authority are the most important virtues children should learn." The GS Aggressive Mistrust scale was also included in the present study, as it would plausibly relate to support for e.g. pre-emptive military action. A sample (negatively scored) item: "Only once in a great while, if at all, does one run into a dishonest and deceitful person." For the main present sample (2015-16 UK) Cronbach's alpha was .78 for authoritarianism and .72 for aggressive mistrust,

With respect to attitudes towards peace and war, a carefully developed and validated contemporary measure is the 16-item one by Bizumic et al. (2013), who found two distinct though modestly negatively correlated dimensions for attitudes towards peace and war respectively (Bizumic et al., 2013). As exemplar items: "We must devote all our energy to securing peace throughout the world" and "War is sometimes the best way to solve a conflict". For Bizumic et al. (2013, study 3, $\mathrm{N}=3930$ ) Cronbach's alpha was .83 for attitudes towards peace and .90 for war. The translation and administration of this measure to the Israeli sample followed the same procedures as for the TIPI.

Additionally, participants responded to a variety of demographic items plus also three bespoke attitude items as follows:

1. Some people argue that America should have a foreign policy of pre-emption whereby they seek out potential threats and intervene to disrupt these potential threats using military force if necessary. Please indicate your overall support for this policy on the following scale. Please use any 
number ranging from 1 (strongly oppose) to 7 (strongly support):

2. In September 2014 the UK Parliament backed British participation in air strikes against extremists in Iraq. Do you think this was the right decision? (Please respond with any number between 1 (definitely wrong) and 7 (definitely right)

3. In light of the recent terror attacks in France/Europe, do you think any immigration/policy changes in the UK would be justified? Why?

At the end of the third question, space was left for free-text responses which, as a separate variable, have been coded from 1 (for more restrictive) to 3 (for less restrictive in light e.g. of refugees' needs). The three questions were translated into Hebrew.

Demographic items included, among others: age, sex, best A-level grades (UK university qualifying exams, where applicable, included here in part as a proxy for intelligence/achievement), size of city/town where brought up (residents of large UK cities tend, e.g., to be more cosmopolitan and less politically conservative), and parents' occupations (subsequently coded for socio-economic status). Participants were also asked how strongly they supported or agreed with each of the main UK political parties as well as with systems of socialism and capitalism. (These were defined respectively as being systems where "in general, whole community collectively owns \& controls property/goods/production" for socialism, and "in general, individuals own \& control land/capital/production" for capitalism).

\section{Procedure}

Because the 2015-16 UK sample is the largest and the data most comprehensive for the present purpose, the results that follow are derived from that sample and then compared, where applicable, with the other samples. 
The various materials were administered either at the ends of lab classes or in special sessions. In order to allow for sequence effects (which turned out not much to matter), the forms for the 2015-16 British sample were arranged in a systematic rota of 48 different sequences of items.

\section{Results}

The various personality measures were scored according to previously validated dimensions.

Table 1 about here

For the Bizumic et al. (2013) scales of attitudes towards peace and war, see Table 1. It should be noted that in the original version the respondents scored the items from -4 to +4 while ours used an equivalent scale from 1 to 9. In our UK 2015-16 sample, using essentially the same factor analytic procedure as Bizumic et al. (oblimin rotation requesting two factors), we found the relative factor loadings for a few items differed (see Table 1 for the loadings we found using oblimin rotation with Kaiser normalisation). One of Bizumic's (negative) peace items (no. 3) instead loaded (positively) on our obtained war factor, and three of the (negative) war items (numbers 5, 11, and 15) instead loaded (positively) on our peace factor. Also, one of the (negative) war items (no. 13) loaded, in our data, both as a negative war item and a positive peace one. We therefore, for data from the UK 2015-16 sample, did our analyses with both, slightly different versions of the peace and war scales--rather than using only the original scales--in order to check whether the few differences would affect our results; but generally they did not. Our two factors were modestly correlated (-.362) with each other.

We first consider the interrelationships of the various personality dimensions and then turn to their associations with attitudes towards peace and war. In reporting variables as being correlated, we generally 
refer to $r$ s that are at least greater than about 0.3 (uncorrected two-tailed $p<.001$ ). Results are based first on the British 2015-16 sample and then, in each section, on the other two samples where applicable.

Personality interrelationships. For the British 2015-16 sample, correlations among the personality dimensions are displayed in Table 2. Rather unusually, (a) Big Five (TIPI) extraversion was (modestly) associated with both Emotional Stability and Openness and (b) SYMLOG Forward (task-oriented) and Positive were associated with each other. As expected (see Blumberg, 2001, mapping Big Five onto SYMLOG): SYMLOG Up (assertiveness) was substantially similar to Big Five Extraversion though not (as also expected) with Big Five Openness; SYMLOG Positive was (modestly) related to Big Five Agreeableness (though not negatively with Emotional Stability), and SYMLOG Forward (task-oriented) was positively correlated with Big Five Conscientiousness (but also slightly with Agreeableness and Extraversion).

Tables 2 and 3 about here

As one might expect, but as is not typically found empirically, Authoritarian Conformity was (negatively) associated with both Big Five Openness (and, to a lesser extent, perhaps with Aggressive Mistrust). Aggressive Mistrust also had modest negative correlations with Big Five Extraversion, Agreeableness, and Emotional Stability.

In the corresponding results from the 2014-15 UK sample: among the Big Five dimensions Extraversion was mildly associated with Openness and (negatively) with Conscientiousness; and Conscientiousness and Emotional Stability were modestly (.35) correlated with each other. As expected (from Blumberg, 2001): SYMLOG Up (assertiveness) was substantially similar to Big Five Extraversion though not (as would also have been expected) with Big Five Openness. Unusually, SYMLOG Positive was 
not associated with Big Five Agreeableness but with Conscientiousness and (slightly) as expected with Emotional Stability. Also as expected, SYMLOG Forward (task-oriented) was associated with Conscientiousness. Authoritarian Conformity and Aggressive Mistrust did not correlate substantially with any of the other personality variables. As expected and supporting the validity of the measures concerned, General Survey Extraversion was substantially correlated with both SYMLOG Up (assertiveness) (.57) and Big Five Extraversion (.64); and Anxiety was negatively correlated with Big Five Emotional Stability (.63) though also modestly negatively with Big Five Conscientiousness (-.42).

Again in the Israeli sample, and as Blumberg (2001) previously found with UK data, SYMLOG Up (assertiveness) was substantially correlated with Big Five Extraversion though not (as also expected) with Big Five Openness; SYMLOG Positive was associated with Big Five Emotional Stability and (modestly) with Agreeableness; and again as expected, SYMLOG Forward (task-oriented) was associated with Conscientiousness. Authoritarian Conformity and Aggressive Mistrust did not correlate substantially with any of the other personality variables.

Attitudes towards war and peace. The two scorings of the peace scale (see above) unsurprisingly correlated highly with each other, and both had similar association patterns with other dimensions. (See Table 3). The same is true for the two war scales, which are also moderately (negatively) associated with the peace scales. Big Five Agreeableness was negatively associated with the war scales and positively with the peace scales. Big Five openness, too, was negatively associated with the war scales and, to a lesser extent, positively with the peace scales. Finally, as one might expect, Authoritarian Conformity was positively correlated with the war scales and, to a lesser extent, negatively with the peace scales.

Demographic variables. In general the above findings showed stability across demographic variables. The present demographic variables were found, moreover, to be independent of each other except for a modest tendency for the females $(\mathrm{N}=127)$ to have grown up in larger cities/towns than males $(\mathrm{N}=$ 
27). They also tended to score higher than males on SYMLOG's Positive (akin to friendliness). Participants who had grown up in smaller towns were found, nevertheless, also to be a bit more extraverted. There was also a trend for higher social class to be associated with more positive attitudes towards peace, and with higher Big Five extraversion and SYMLOG Up (assertiveness).

There was a slight tendency for the older students to score lower on Aggressive Mistrust. As one might predict, the female students tended to score more positively than males on attitudes towards peace and show a trend towards being lower on attitudes towards war and Aggressive Mistrust.

In the 2014-15 UK sample, too, the measured demographic variables were largely independent of each other and of the personality and attitude measures. Older students tended to have better A-level grades, however, and to score higher on Big Five Openness; and males tended to score higher on Big Five Emotional Stability.

In the Israeli sample, the measured demographic variables were, as with the UK data, largely independent of each other and of the personality and attitude measures. Again, the bespoke attitude measures were moderately correlated with each other and with the Attitudes towards War scale as well as with political right-wing support. Authoritarianism was significantly correlated with the first attitude measure (US pre-emption) though not with the second one (UK air strikes). The older participants were more Left-leaning and less authoritarian. The Peace and War scales were negatively correlated with each other and aligned with Left- and Right-wing political views respectively.

Bespoke attitude items. Degree of endorsements of America pre-empting threats and Britain participating in air strikes in Iraq were highly correlated with each other and with the war scale and (negatively) the peace scale (see Table 3). Such results are unsurprising but help provide mutual validation for the war/peace scales and for the contemporary-event attitude items. Just over $60 \%$ of respondents disagreed with endorsing the first item on pre-emption (with a further $15 \%$ neutral), and fully $70 \%$ disagreed 
with the second item (and a further 17\% were neutral). There was also a trend for more restrictive immigration policies--the remaining bespoke attitude item--to be aligned with such endorsements. The only further moderate correlation of these items with personality and demographic variables was with authoritarianism (though for the second bespoke attitude item, the correlation was only .2).

Peace/War, personality, and political variables. The political items (degree of support or agreement with particular political parties and with socialism and capitalism) showed some associations with each other and some with other attitude, personality, and demographic variables. Although one might predict that support of one political party would be negatively correlated with that for opposition parties, in fact these inter-party correlations were mainly negligible. The only one above .25 was .38 between the Greens and the Liberal Democrats, both being mainly left-centrist minority parties.

Remarkably, the only moderately strong (and probably predictable) correlations between favouring a political party and the peace/war variables were with Conservatives, positive for war and military action and negative for peace. (Although there is substantial dispersion of the attitude variables at every level of Conservative support, the association effect is not concentrated at any particular levels--except that there are few moderate Conservative supporters in our sample and no strong ones.) To some extent, and also expected, was the reverse pattern for endorsing Greens.

Endorsing socialism and capitalism were positively associated with, respectively, support of Labour and Conservative political parties, consistent with their core ideologies. Additionally, our third attitude item--favouring less restrictive immigration policies e.g. in light of refugees' needs--is positively associated with supporting socialism and negatively with capitalism (and to a lesser extent negatively with supporting Conservatives). Otherwise, support for the various political parties and for socialism or capitalism has remarkably low association with all of the demographic and personality variables here measured. Exceptionally, authoritarian conformity has a modestly positive correlation with Conservative support and 
negative with Greens. Finally, being observant in one's religion (if any) tends to be positively associated with endorsing capitalism and negatively with social class.

As with the later larger UK sample just covered, in the 2014-15 UK sample the degree of endorsements of America pre-empting threats and Britain participating in air strikes in Iraq were highly correlated with each other. The only other moderate correlations of these items were, again, with authoritarianism and with favouring the Conservative political party. Support for Liberal Democrats was again correlated with that for Greens; and, given the coalition government at the time, with Conservatives as well.

Israeli sample. The main findings from the UK samples are broadly similar to those from the Israeli sample; though again, some of the smaller correlations differed, as one might expect.

\section{Discussion}

The main objective of the present study has been met, namely to document some links between general and contemporary bespoke attitudes towards peace and war and various personality and demographic variables, in particular showing a variety of associations that were largely expected but apparently not previously documented. The main findings were verified in both of two quite different Western countries and at the very least provide hypotheses to test within general populations.

One can moreover make some prescriptive inferences. Deutsch (2011) has identified two basic types of goal interdependence: positive--where parties' goals are mutually linked (they "sink or swim together") or negative, where the likelihood of one party's goal attainment is negatively associated with that for the other party. Cross-cutting this distinction, Deutsch also posits two basic types of action by each party: "effective actions," which facilitate goal attainment, and "bungling actions," which worsen the likelihood of obtaining a goal. Generally speaking, conflict resolution rests on the parties moving away from negative 
interdependence and doing so in an effective, constructive manner.

Depending on specific circumstances and on the causal linkages among verifiably correlated personality and attitude variables, which might well be bi-directional, interventions that address one element measured in the present study, such as authoritarianism or prioritizing military intervention, might well affect others and may also move parties away from negative interdependence and also towards effective actions.

To take just one example, the Jigsaw Classroom method that Aronson (1978) "invented" in the 1970s demonstrated that positive goal interdependence can change people's attitudes towards each other. "But what happens when the people in conflict have no way to create a common goal? How can we reduce instrumental aggression when the goal is the exact opposite of the goal of the other and so the person believes that he/she has the 'right' to use anything to achieve that goal, and he/she dehumanizes the opponent? When there is no way of reasoning because of common cognitive distortions (delineated by Galluccio \& Beck, 2015) such as dichotomous ('black and white') thinking, tunnel vision, over-generalization, selective abstraction, disqualifying the positive (e.g. in adversaries) and (specious) mind reading? ... Prevention and teaching cooperation, sensitivity, and empathy would be much more effective than to 'fight' a fully grown aggression" (P. Hajdu, personal communication, September 11, 2015).

In addition to the "jigsaw" method, widely documented as successful (if not widely adopted), one might posit that a less hierarchical procedure would be worth testing, where participants themselves (with facilitators) decide on the important "pieces" of their "puzzles".

In considering attitudes in the present contexts at least two extensions of the present work would seem to be worthwhile. One relates to the distinction between overt, possibly traditional views as regards e.g. war and peace vs. latent proclivities favouring aggression or conciliation. The distinction could be addressed with use of Implicit Association Tests (IATs) (Greenwald et al., 1998; see also Azar, 2008) 
measured in tandem with the present, more overt self-report measures.

Another related and important relevant distinction is among compliance, identification, and internalization (as initially articulated by Kelman, 1961). One does not know what mix the attitude responses in the present research might reflect--compliance with implicit demand characteristics and/or socially desirable views, inner identification with the views put forward or with the groups thought to espouse them, and more deeply felt internalization. These could be separated experimentally in an effort better to understand both the espoused attitudes themselves and their links with personality variables.

Even for existing contemporary, seemingly intractable conflicts, however, such as countering Islamic State, the present array of personality/attitude correlates taken together with e.g. Deutsch's paradigm suggests evidence-based advice. For example: "What ISIS is trying to do is drive an escalation/dehumanization spiral to the point of producing a catastrophic and apocalyptic war between the West and the Islamic world. Our central objective should be preventing this strategy from working. Bombing civilians in the hope of killing a few (or even many) ISIS operatives likely will do the opposite" (Heidi and Guy Burgess in: “Can psychology find a path to peace?”, 2016, p. 112).

Summary of some main findings and practical implications. The present data have (a) largely replicated the factor structure underlying Bizumic et al.'s (2013) measures of attitudes toward peace and war and moreover (b) found these attitudes to be associated with some specific contemporary views as regards terrorist attacks and degree of justifiability for a foreign policy of pre-empting threats by using military force.

The current results also confirm that authoritarianism, in particular, is associated with the aforementioned attitudes and views--more strongly than other, more recently developed personality measures such as the Big Five (Five Factor) dimensions. Political conservatism was found to be associated with authoritarianism and with positive attitudes towards war and negative prioritising of peace; these 
findings are unsurprising but add to one's confidence in the validity of the present data.

Three desiderata for use of these findings, particularly as regards authoritarianism and attitudes towards war and peace, may be to avoid under- or over-estimating their importance and, thirdly, to contextualise them.

Even in a somewhat homogeneous group such as psychology undergraduates, authoritarianism (and to some extent other personality variables), and presumably its almost eponymous characteristic of obedience to authority, continues to be associated with attitudes of current importance. A present flavour of authoritarianism in Western Europe and America might, though, represent support of populist authority. Intriguingly, it may be some of the people who are likely to be authoritarian (e.g. those who are poor and less educated) that are most likely to distrust their own mainstream governments and perhaps, for instance, to exaggerate the extent of threats posed by immigrants and underestimate the benefits they bring.

Although understanding the role of authoritarianism vis-a-vis matters of peace and conflict seems clearly worthwhile, the ways in which findings might be applied to interventions represents a legitimate area of academic debate. To take just one example, Dear (2016) has argued that efforts to counter (no doubt highly authoritarian) terrorists and insurgents are worth pursuing but may most effectively be directed toward changing the perceived efficacy of their means (presumably to shift from violence to nonviolence) rather than of their values and goals.

It is worth remembering that authoritarianism is not static. It is known generally to decrease developmentally with education, for example. Do shifts in authoritarianism also lead to changes in attitudes toward peace, war and conflict resolution? In any case, how do the levels on these variables spread and aggregate within groups? These questions should be further examined empirically.

It would also be worthwhile and probably straightforward to check whether integrative complexity (IC) shares substantial variance with authoritarianism in conflict situations. This would seem very plausible 
given that the two tend to be aligned, for example with political conservatism, though authoritarianism is largely a "trait" dimension whereas IC is closer to a "state" characteristic (Jost, Glaser, Kruglanski, \& Sulloway, 2003; Suedfeld, Guttieri, \& Tetlock, 2005). IC is known to have increased presence among policy makers in times of crisis; but, across crises, lower IC (for even one party in a conflict) is associated with better outcomes for all parties (Janis, 1972; Suedfeld \& Tetlock, 1977). Can interventions to lower authoritarianism and/or IC in such contexts be successfully carried out? What are the ethical implications of doing so?

As regards not over-estimating authoritarianism's importance: it and the other major personality variables that we measured apparently account for only a limited amount of the variance associated with peace/war attitudes. To look at broader systems including a variety of factors--as Valacher, Coleman and Nowak (2012) have outlined--would represent a substantial but worthwhile endeavour. Such an effort should no doubt include, but not be limited to, four functional "AGIL" areas delineated by Parsons and his followers (see e.g. Hare, 1983; Ritzer \& Smart, 2001): economic and informational Resources ("Adaptation"), people's actual activities and motivation in getting on with their relevant tasks ("Goal Attainment"), Interpersonal influence ("Integration"), and people's Values ("Latency"). Although personality is implicit in "Values", the present findings suggest that personality, particularly (in the present context) authoritarianism, ought to be added more explicitly to the AGIL mix.

Finally, there is a need to replicate the present work in other contexts and to explore further the psychological, social and biological mechanisms that underlie the present findings. Ordinarily, one might wonder whether findings based on a limited population might disappear (and perhaps be "replaced" by other effects) in a demographically different sample of respondents. In the present instance, however, (a) our main British findings e.g. with regard to authoritarianism were at least largely replicated in a quite different country and, moreover, (b) our main sample of undergraduates in London show a substantially restricted 
range (a preponderance of low authoritarians) which would in principle considerably under-estimate the true size of the effects found.

Moving further into speculative realms, one might envision the study of links between authoritarianism (which may be associated with sub-optimal response to conflict and crises) and stresses such as those associated with conflict to yield theoretical and practical gains by expanding into explanations based partly on cognition-mediated neuroscience. As an example of the kind of research that might be envisaged, an experimental study by Alia Crum (described in "Stress", 2016; cf. Crum \& Phillips, 2015) found that participants with a flexible belief that moderate stress enhances performance were more likely to seek feedback after an uncomfortable speaking engagement.

Seeing stressors as challenges rather than threats invites physiological responses that improve thinking and cause less physical wear and tear. ... When people believe they are being challenged rather than threatened, the heart still beats faster and adrenalin still surges, but the brain is sharper and the body releases a different mix of stress hormones, which aid in recovery and learning. The blood vessels remain more open and the immune system reacts differently, too. ... Attitudes and beliefs [such as watching a video extolling the way stress can improve performance and forge social connections can] shape the physical response to stress ("Stress", 2016, p. 49).

In general--and in conclusion: findings from both laboratory and field studies have consistently demonstrated the importance of personality variables in negotiation processes and have explored a variety of personality factors that relate to whether participants are (or see themselves as) positively or negatively interdependent and whether their actions are likely to be effective or "bungling", thus rendering negotiations productive or nonproductive.

A wide range of empirical studies connects personality traits of decision-makers to their patterns of negotiation. The present research looks at associations among potentially relevant personality variables. The 
hope is to contribute to an organizational scheme shaped by personality structure and bearing implications for optimal negotiations.

In terms of Deutsch's paradigm, our results do show individual differences in, and associations among, variables that would relate to the perhaps remediable likelihood of particular parties being differentially likely to find themselves (a) in negatively vs. positively interdependent situations and (b) carrying out effective instead of "bungling" actions.

\section{References}

Aronson, E. (1978). The Jigsaw Classroom. Beverly Hills, CA: Sage.

Azar, B. (2008, July-August). IAT: Fad or fabulous? [APA] Monitor on Psychology, 39 (7), 44.

Bales, R. F., \& Cohen, Stephen P. (1979). SYMLOG: A system for the multiple level observation of groups. New York, NY: Free Press.

Bizumic, B., Stubager, R., Mellon, S., Van der Linden, N., Iyer, R., \& Jones, B. M. (2013). On the (in)compatibility of attitudes toward peace and war. Political Psychology, 34, 673-693.

Blumberg, H. H. (2001). The common ground of natural language and social interaction in personality description. Journal of Research in Personality, 35, 289-312.

Blumberg, H. H. (2006). A simplified version of the SYMLOG Trait Rating Form. Psychological Reports, 99, 46-50.

Blumberg, H. H., Hare, A. P., \& Costin, A. (2006). Peace psychology: A comprehensive introduction, Cambridge, England: Cambridge University Press.

Blumberg, H. H., Zeligman, R., Appel, L., \& Tibon-Czopp, S. (2015, September). An overview of the recent psychological literature on cooperation and conflict. Paper presented at the Conflict Research Society conference, University of Kent, Canterbury, Kent, England.

“Can psychology find a path to peace?” (2016, February), The Psychologist, 29(2), 108-113. [Special 
feature in February 2016 issue]. Available at:

https://thepsychologist.bps.org.uk/can-psychology-help-us-out-mess

Costa, P. T. Jr., \& McCrae, R. R. (1985). The NEO Personality Inventory. Odessa, FL:

Psychological Assessment Resources.

Crum, A., \& Phillips, D. J. (2015). Self-fulfilling prophesies, placebo effects, and the socialpsychological creation of reality. In R. A. Scott \& S. M. Kosslyn (Eds.), Emerging trends in the social and behavioral sciences (14 pp.). Hoboken, NJ: John Wiley and Sons.

Dear, K. (2016, July). The psychology of terrorism and how to respond. Paper presented at an SPSSI-UK symposium: The Psychology of Equality, Security, and Human Rights in the UK Context, University of Kent at Canterbury.

Deutsch, M. (2011). Cooperation and competition. In P. T. Coleman, (Ed.), Conflict, Interdependence, and Justice: The Intellectual Legacy of Morton Deutsch (pp. 23-40). Springer Science + Business Media: New York, NY.

Eckhardt, W., \& Alcock, N. Z. (1970). Ideology and personality in war/peace attitudes. The Journal of Social Psychology, 81(1), 105-116.

Fiske, D. W. (1949). Consistency of the factorial structures of personality ratings from different sources. Journal of Abnormal and Social Psychology, 44, 329-344.

Galluccio, M., \& Beck, A. T. (2015). A cognitive insight on cooperation and conflict. In M. Galluccio (Ed.), Handbook of international negotiation: Interpersonal, intercultural, and diplomatic perspectives (pp. 229-243). New York, NY: Springer..

Gosling, S. D., Rentfrow, P. J., \& Swann, W. B. (2003). A very brief measure of the Big-Five personality domains. Journal of Research in Personality, 37, 504-528.

Greenwald, A. G., McGhee, D. E., \& Schwartz, J. K. L. (1998). Measuring individual differences in 
implicit cognition: The Implicit Association Test. Journal of Personality and Social Psychology, 74, 1464-1480.

Hare, A. P. (1983). A functional interpretation of interaction. In H. H. Blumberg, A. P. Hare, V.

Kent, \& M. F. Davies, Small groups and social interaction (Vol. 2, pp. 429-447). Chichester, England: John Wiley.

Janis, I. L. (1972). Victims of groupthink: A psychological study of foreign-policy decisions and fiascoes. Boston: Houghton, Mifflin.

Jost, J. T., Glaser, J., Kruglanski, A. W., \& Sulloway, F. J. (2003). Political conservatism as motivated social cognition. Psychological Bulletin, 129, 339-375.

Kelman, H. C. (1961). Processes of opinion change. Public Opinion Quarterly, 25, 57-78.

Kritzer, H. M., Hare, A. P., \& Blumberg, H. H. (1974). The General Survey: A short measure of five personality dimensions. Journal of Psychology, 86, 165-172.

Page, K. (1931, May). Nineteen thousand clergymen on war and peace. World Tomorrow, 14, 138-149.

Peabody, D., \& Goldberg, L. R. (1989). Some determinants of factor structures from personality-trait descriptors. Journal of Personality and Social Psychology, 57, 552-567.

Ritzer, G., \& Smart, B. (2001). Handbook of social theory. London: Sage.

“Stress.” (2016, July 23-29). Stress: What makes us stronger. Economist, 420(8999), 48-49.

Suedfeld, P., Guttieri, K., \& Tetlock, P. E. (2005). Assessing integrative complexity at a distance: Archival analyses of thinking and decision making. In J. M. Post (Ed.), The psychological assessment of political leaders: With profiles of Saddam Hussein and Bill Clinton (pp. 246-270). Ann Arbor, MI: The University of Michigan Press.

Suedfeld, P., \& Tetlock, P. (1977). Integrative complexity of communications in international crises. 
Journal of Conflict Resolution, 21, 169-184.

Thrall, C. A., \& Blumberg, H. H. (1963). Attitudes of the American Protestant clergy toward issues of war and peace. Fellowship, 29(17), 3-9.

Tibon, S. (1998), Personality traits and national dilemma: Psychological perspectives on attitudes toward the peace process in the Middle East. (Unpublished doctoral dissertation). Goldsmiths College, University of London, England.

Tibon, S., \& Blumberg, H. H. (1999). Authoritarianism and political socialization in the context of the Arab-Israeli conflict. Political Psychology, 20, 581-591.

Tibon-Czopp, S., \& Weiner, I. B. (2016). Rorschach Assessment of Adolescents: Theory, Research, and Practice. New York, NY: Springer.

Vallacher, R., Coleman, P. T., \& Nowak, A. (2012). Dynamical systems theory: Applications to peace and conflict. In D. J. Christie (Ed.), Encyclopedia of peace psychology (Vol. 1, pp. 371-375), Hoboken, NJ: Wiley-Blackwell. 
Table 1

Factor Loadings for Items Measuring Attitudes towards Peace and War

\begin{tabular}{|c|c|c|}
\hline Item & $\begin{array}{l}\text { Pattern Matrix } \\
\text { Component }^{\mathrm{a}}\end{array}$ & $\begin{array}{c}\text { Structure Matrix } \\
\text { Component }\end{array}$ \\
\hline & 12 & 122 \\
\hline
\end{tabular}

\section{Attitudes towards Peace Scale}

1. We must devote all our energy to securing peace throughout the world.

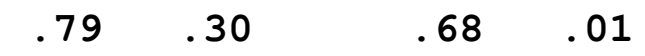

3. People who place a high value on peace are usually weak and cowardly. (R) $\quad \begin{array}{llllll}.5 & .56 & -.08 & .51\end{array}$

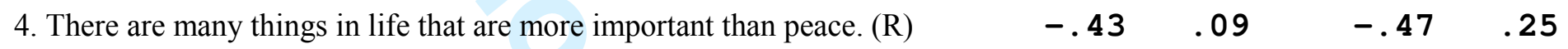

6. Our country's first priority should be world peace. $\quad \begin{array}{llll}74 & .07 & .71 & -.20\end{array}$

8. In general, I am not too concerned about peace in the world. (R) $\quad \begin{array}{lllll}\text { R } & -.53 & .06 & -.56 & .25\end{array}$

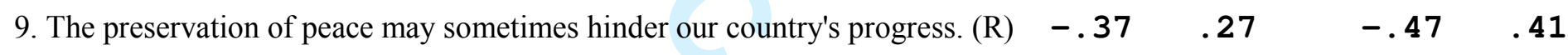

10. Peace brings out the best qualities in a society. $\quad \begin{array}{llll}76 & .05 & .74 & -.22\end{array}$

14. I believe that peace is extremely important. $\quad \begin{array}{llll}.83 & .03 & .82 & -.27\end{array}$

Attitudes towards War Scale

2. The desirable results of war have not received the attention they deserve. $\quad \begin{array}{lllll}.10 & .72 & -.16 & .68\end{array}$

5. War is a futile struggle resulting in self-destruction. (R) $\quad .49-.18 \quad-56 \quad-.36$

7. Although war is terrible, it has some value. $\quad-.25 \quad .68 \quad-.49 \quad .76$

11. The evils of war are greater than any possible benefits. (R) $\quad \begin{array}{llll}\text { (R) } & -.31 & .56 & -.47\end{array}$

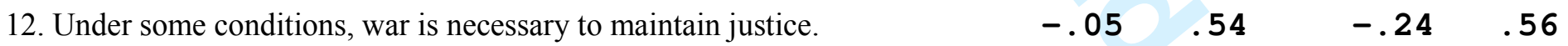

13. There is no conceivable justification for war. (R) $\quad \begin{array}{llll}\mathrm{R}) & -.35 & .35 & -.43\end{array}$

15. War breeds disrespect for human life. (R) $\quad \begin{array}{llll}.53 & -.15 & .58 & -.34\end{array}$

16. War is sometimes the best way to solve a conflict. $\quad-.19 \quad .74 \quad-.45 \quad .80$

Note. $(\mathrm{R})=$ Reverse/negatively scored items. $\quad{ }^{\mathrm{a}}$ Rotation converged in 7 iterations.

In Bizumic et al.'s (2013) principal component analysis plus oblimin rotation, with samples from the USA $(\mathrm{N}=112)$ and

Denmark $(\mathrm{N}=596)$, all item loadings were over .30 (median 62.5) on their respective scales (except item 9 with a .16

loading in their Danish sample), and all items showed loadings under .25 in both samples on the "other" scale. 


\section{Table 2.}

\section{Correlations among Personality Variables}

\begin{tabular}{|c|c|c|c|c|c|c|c|c|c|}
\hline 8 & 1 & 2 & 3 & 4 & 5 & 6 & 7 & 8 & 9 \\
\hline 1. tipi ext & & & & & & & & & \\
\hline 2. tipi agr & .01 & & & & & & & & \\
\hline 3. tipi consc & .01 & .14 & & & & & & & \\
\hline 4. tipi emo.sta & $.21 *$ & .05 & .14 & & & & & & \\
\hline 5. tipi open & $.22 *$ & .14 & .07 & .05 & & & & & \\
\hline 6. symlog up & $.54 \star \star \star$ & -.08 & -.03 & .12 & .17 & & & & \\
\hline 7. symlog pos & $.20 *$ & $.25 * *$ & -.03 & .02 & .06 & .13 & & & \\
\hline 8. symlog fwd & $.28 * \star$ & $.22 \star$ & $.30 * \star \star$ & .01 & .07 & $.23 *$ & $.44 * \star \star$ & & \\
\hline 9. gs agg & $.26 * \star$ & $-.23 *$ & .08 & $-.22 \star$ & .01 & .04 & -.14 & -.18 & \\
\hline 10. gs conf & .04 & -.03 & -.01 & .06 & $-.37 * \star \star$ & -.09 & .17 & $.19 *$ & $-.23 *$ \\
\hline
\end{tabular}

Note. Due to some items being on a rota among subsamples and there also being a small amount of other missing data, N varies from 108 to 112; except: TIPI (“Big Five") internally \& with age and sex, 150 to 157 ; socio-economic status $=59$ to 86 with all other variables; sum A-levels $\&$ city size (digits) with peace/war, symlog \& gen surv $=75$ to 85 .

Variable names use the following abbreviations. For the tipi "Big Five" dimensions: ext = extraversion; agr $=$ agreeableness $;$ consc $=$ conscientiousness $;$ emo.sta $=$ emotional stability; and open $=$ openness. For the symlog diomensions, up refers to dominance; pos = positive; and fwd(forward) refers to task/serious/predictable. For the General Survey (gs), agg and conf refer respectively to measures of aggressive mistrust and authoritarian conformity.

$* \mathrm{p}<0.05$ level (2 tailed). $* * \mathrm{p}<0.01$ level ( 2 tailed). $* * * p<0.001$ level $(2$ tailed $)$ 
Table 3

Correlations among Personality and Attitude Variables

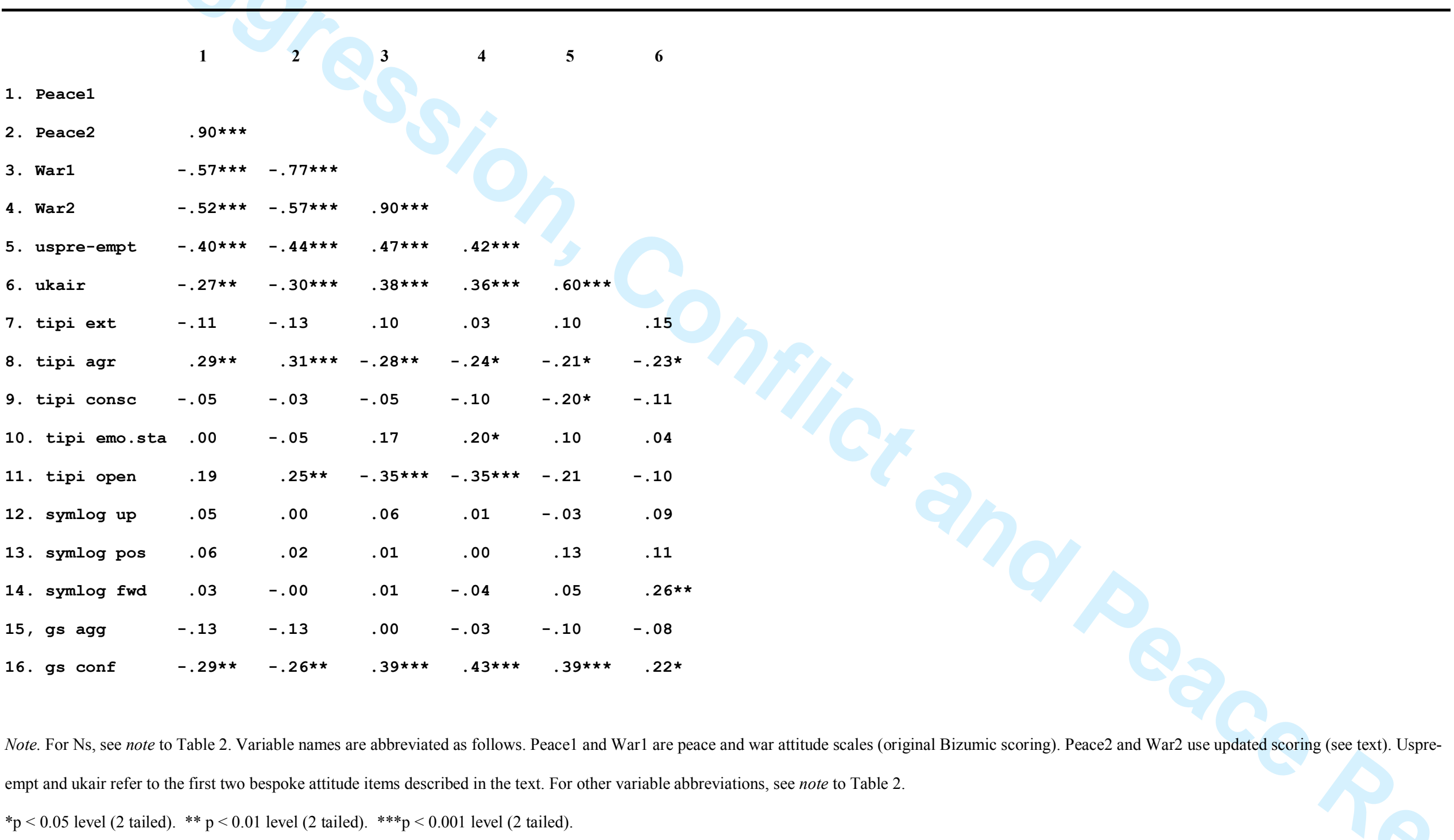

